\title{
Sleep Disturbances in Seniors with Parkinson's Disease
}

\author{
S. Putekova (Silvia Putekova), J. Martinkova (Jana Martinkova), \\ M. Hutkova (Maria Hutkova)
}

Trnava University in Trnava, Faculty of Health Sciences and Social Work,

Department of nursing, Slovakia.

\section{E-mail address:}

silvia.putekova@truni.sk

\section{Reprint address:}

Silvia Putekova

Trnava University in Trnava

Faculty of Health Sciences and Social Work

Department of nursing

Univerzitne Nam.1

91843 Trnava

Slovakia

Source: Clinical Social Work and Health Intervention

Volume: 11

Issue: 4

Pages: $68-77$

Cited references: 28

\section{Reviewers:}

Mageswaari Rajoo

Bangkok, Thailand

Selvaraj Subramanian

Kuala Lumpur, Malaysia

\section{Keywords:}

Sleep. Senior. Parkinson's Disease. Sleep Disturbances. Nursing care.

\section{Publisher:}

International Society of Applied Preventive Medicine i-gap

CSWHI 2020; 11(4): 68 - 77; DOI: 10.22359/cswhi_11_4_10 (C) Clinical Social Work and Health Intervention

\section{Abstract:}

Introduction:The prevalence of sleep disturbances in patients with Parkinson's disease is very high. It is one of the factors that significantly affects the health care, nursing care and also quality of life of patients and their family members.

Design: For the purpose of the research, design of a prospective quantitative study was chosen based on an assessment scale.

Aim: The research aim was to map out the prevalence of sleep disturbances in patients with Parkinson's disease and to find out the influence of sex (gernder) and stage of the disease on the sleep disturbances prevalence.

Methods: We used the Parkinson's Disease Sleep Scale PDSS2 to assess the symptoms of sleep disturbances. We statistically 
computed the results using the chi-square test and Mann- Whitney $U$ test. The research sample consisted of 220 respondents diagnosed with Parkinson's disease, who were included in the sample on the basis of deliberate selection.

Results: Out of the total respondents, 115 (52.3\%) show mildly severe sleep disorder according to the score of the sleep scale from 0 to $20 ; 67(30.5 \%)$ respondents show moderate sleep disorder; $38(17.3 \%)$ show severe sleep disorder according to the score of the sleep scale from 21 to 40 . The median score was higher in women (20.5) compared to men (19) with no statistical significance $(\mathrm{p}=0.646)$. When comparing sleep disturbances by the stage of the disease, the median score was 10.5 at an early stage while 10.0 at advance stage, this difference was not significant ( $\mathrm{p}$ value $=0.477)$.

Conclusion: The issue of the sleep disorders prevalence in patients with Parkinson's disease is highly urgent. In conclusion, we can state that neither sex (gender) nor the stage of the disease has a clear effect on the manifestations of sleep disturbances in patients with Parkinson's disease.

\section{INTRODUCTION}

Sleep plays an important role in a person's good health and well-being throughout life. Sufficiency of quality sleeping protects our mental and physical health, quality of life and safety (Doktorova 2018). More than $40 \%$ of seniors have problems with falling asleep and sleep as such. Spira et al. (2012) states that sleep issues in seniors are usually associated with health problems as well as changes in daily activities and reduced mobility. Research shows that the main cause of deteriorating sleep quality is not age, but diseases that affect the elderly. Limited social contacts also contribute to the state of worsened sleep, which results in a decrease in physical activity in outdoor areas (Plhakova 2013).

Parkinson's disease is a progressive degenerative neurological disease occurring in older adults that requires long-term health care and nursing care also (Shin \& Hendrix 2013). The disease is characterized by a set of basic motor symptoms that include: rigidity; bradykinesia; tremors; postural instability (Kalia \& Lang 2015). Bares et al. (2015) include other motor symptoms including: poor upright posture; slow walking; micrography; masked face; decreased blinking frequency; blepharospasm; dysphagia; dysarthric speech; foot and thumb dystonia; rigidity in gentle upper limb movements. Parkinson's disease is often considered to be a movement disorder manifested by motor symptoms. In addition to the motor symptoms that define the diagnosis of the disease, there is a wide range of non-motor symptoms that patients may suffer from and which reduce their quality of life. Nonmotor symptoms are not only common, but also insufficiently reported by patients and their caregivers or healthcare professionals (Maass \& Reichmann 2013). Non-motor symptoms are receiving more and more attention and can often affect the patient much more than motor symptoms.

We divide non-motor symptoms into 4 categories: 1) autonomic dysfunctions (gastrointestinal discomfort, increased salivation, eye accommodation disorders), 2) mental disorders (mood changes, cognitive deficits, psychoses, depression), 3) pain, 4) sleep disorders (Havrankova et al. 2016). Sleep disorders include: sleep fragmentation, daytime somnolence, breath disorder during sleeping, restless legs syndrome and nightmares. They occur in 60 to $98 \%$ of patients with Parkinson's disease (Swick, 2012). Non-motor symptoms have received little attention for several years, but now these symptoms are known to be significant predictors of morbidity in determining quality of life, disease costs and degree of institutionalization (Havrankova et al., 2016). Although Parkinson's disease primarily affects mobility, it is clear that it is not the only manifestation of this disease and there are a number of other symptoms, including sleep disorders and vigilance maintaining. Figuratively speaking, a patient with Parkinson's disease 
never sleeps (Dusek 2010). Bargiotas et al. (2016) state that although James Parkinson described sleep disorders as part of the clinical picture in his observations in 1817, interest in sleep disorders did not increase until the $20^{\text {th }}$ century. In the disease, sleep disorders and excessive daytime sleepiness are multifactorial complex issues and are secondarily caused by motor and non-motor symptoms, as well as primary sleep disorders. Sleep disorders include restless legs syndrome and REM sleep behavior.

In order to successfully address sleep disorders in patients with Parkinson's disease, a detailed assessment is required. Depression results in the most common sleep disorders associated with frequent nocturnal arousals and anxiety and their solution lies in the treatment of this disease (Benetin et al. 2014). Sleep disorders are a common non-motor complication that have a major impact on the quality of life of patients and relatives. They can manifest at any stage of the disease and usually become more severe as the disease progresses. Because sleep is a basic and essential physiological need for humans, most patients with Parkinson's disease complain of sleep disorders. The burden caused either directly or indirectly by these symptoms is enormous. Symptoms of sleep disorders that have been documented include: insomnia of several types; including difficulty falling asleep or staying asleep; excessive daytime sleepiness; sleep disturbance with eye accommodation; restless legs syndrome; periodic limb movements in sleep as well as during vigilance (Sobreira-Neto et al. 2017). Sleep disorders are not only associated with a significant deterioration in patients' quality of life, but are also associated with a greater need for health care and nursing care (Bartolomei et al. 2018).

The aim of the research was to map out the prevalence of sleep disturbances in patients with Parkinson's disease and to determine the influence of sex (gender) and stage of the disease on the prevalence of sleep disturbances.

\section{METHODS AND STUDY GROUP}

The design of a cross-sectional quantitative study performed on the basis of a questionnaire survey was chosen for this research. The method of the respondents choosing was intentional. The criteria for including the respondent into the research sample was: the diagnosis of Parkinson's disease and age over 60 years. The study group consisted of 220 respondents, of which $128(58 \%)$ were men and 92 (42\%) women. The youngest respondent of both sexes was 50 years old and the oldest man was 88 years old and the woman 85 years old. The average age of the respondents was 76.8 years. The early disease group consisted of $128(58 \%)$ patients and advanced disease stage group consisted of 92 (42\%) patients. Although the set of respondents was not evenly distributed, the individual groups were statistically comparable.

We used the Parkinson's Disease Sleep Scale, PDSS-2 to assess sleep disorders in patients with Parkinson's disease. PDSS-2 is a specific 15-point self-assessment scale that preferentially assesses sleep disorders. It consists of 15 questions related to various sleep and nocturnal disorders, focusing on the frequency of nocturnal symptoms in patients in the last 7 days. The sleep scale is divided into three domains 1) nocturnal motor symptoms, 2) nocturnal symptoms of Parkinson's disease, 3) disturbed sleep. The patient evaluates each question in one of five categories from 4 - very often (6 - 7 times a week), 3 - often (4 - 5 times a week), 2 - sometimes (2 - 3 times a week), 1 - occasionally (once a week) to 0 (never) except for item 1 , which is the reverse of the rating. After the sum of points for all 3 domains, the total score ranges from 0 (no failure) to 60 (maximum nocturnal failures). Each domain individually scores from 0 to 20 . The assessment scale was edited by additional demographic data of sex (gender) and stage of the disease.

The research took place in the period from January 2019 to October 2019 in four neurological outpatient clinics in the Trnava region. We used descriptive statistics, then chi-square test to test significant differences in proportions and the MannWhitney U test to test significant differences in medians of score. For testing of followed influences, a significance level of $p$ value less 0.05 was set. Individual items from the assessment scale were used. The obtained data were processed using Microsoft Office Excel and analyzed in SPSS 16.0.

\section{RESULTS}

The prevalence of sleep disorders in patients with Parkinson's disease is high and diverse. Our research found that according to the overall Parkinson's Disease Sleep Scale score, each respondent had some sleep disorder. Out of total, 115 (52.3\%) respondents show mild severe sleep disorders according to the score scale from 0 to 20 , of which $74(57.8 \%)$ are men and $41(44.5 \%)$ are women. 
Moderate sleep disorder was present in 67 (30.5\%) respondents according to the score scale from 21 to 40 , of which $33(25.8 \%)$ are men and $34(37.0 \%)$ are women. Severe sleep disorder was showed by $38(17.3 \%)$ respondents according to the score scale from 41 to 60 , of which $21(16.4 \%)$ are men and $17(18.5 \%)$ women. There was no significant difference in men and women proportion by chi- square test $(\mathrm{p}=0.127)$.

The highest recorded score in our research sample was 47 . We did not record a score of more than 50 points in our research sample. Median value reached 19.5 in total assessment score, while for men 19.0 and for women 20.5. This difference was not significant by using Mann-Whitney $U$ test $(\mathrm{p}=0.127)$ (Figure 1).

Figure 1: The total score of the assessment scale, $n=220$.

\begin{tabular}{|c|c|c|c|c|c|c|c|c|c|c|}
\hline \multirow[t]{2}{*}{ Score } & \multicolumn{3}{|c|}{ Total, $n=220$} & \multicolumn{3}{|c|}{ Male, $n=128$} & \multicolumn{3}{|c|}{ Female, $n=92$} & \multirow[t]{2}{*}{$p$ value } \\
\hline & $n$ & $\%$ & median & $n$ & $\%$ & median & $n$ & $\%$ & median & \\
\hline $0-20$ & 115 & 52.3 & 19.5 & 74 & 57.8 & 19.0 & 41 & 44.5 & 20.5 & $0.127 \times 2=4.131$ \\
\hline $21-40$ & 67 & 30.5 & & 33 & 25.8 & & 34 & 37.0 & & $0.646 Z=-0.051$ \\
\hline $41-60$ & 38 & 17.3 & & 21 & 16.4 & & 17 & 18.5 & & \\
\hline
\end{tabular}

\% percentage; $x 2$ value of chi-square test; $Z$ value of Mann-Whitney $U$ test

We performed the analysis of the achieved scores for its individual domains: nocturnal motor symptoms, nocturnal symptoms of Parkinson's disease and disturbed sleep. We divided the achieved score into three categories: from 0 to 10 , from 11 to 16 and from 17 to 20 . We performed the analysis for the whole group, then according to the sex (gender) and according to the current stage of the patients' disease. The results are presented in Figure 2 and Figure 3. The maximum achievable score for each domain is 20.

Figure 2: Total sleep scale score by sex of respondents.

\begin{tabular}{|c|c|c|c|c|c|c|c|c|c|c|}
\hline \multicolumn{11}{|c|}{ Nocturnal motor symptoms } \\
\hline \multirow[t]{2}{*}{ Score } & \multicolumn{3}{|c|}{ Total, $\mathrm{n}=\mathbf{2 2 0}$} & \multicolumn{3}{|c|}{ Male, $n=128$} & \multicolumn{3}{|c|}{ Female, $n=92$} & \multirow[t]{2}{*}{ p value } \\
\hline & $\mathbf{n}$ & $\%$ & median & $n$ & $\%$ & median & $\mathbf{n}$ & $\%$ & median & \\
\hline $0-10$ & 140 & 63.6 & 9.0 & 82 & 64.1 & 8.5 & 58 & 63.0 & 8.0 & $0.410 \times 2=1.803$ \\
\hline $11-16$ & 75 & 34.1 & & 41 & 32.0 & & 34 & 37.0 & & $0.819 \quad Z=-0.228$ \\
\hline $17-20$ & 5 & 2.3 & & 5 & 3.9 & & 0 & 0 & & \\
\hline \multicolumn{11}{|c|}{ Nocturnal symptoms of Parkinson's disease } \\
\hline \multirow[t]{2}{*}{ Score } & \multicolumn{3}{|c|}{ Total, $\mathbf{n}=\mathbf{2 2 0}$} & \multicolumn{3}{|c|}{ Male, $n=128$} & \multicolumn{3}{|c|}{ Female, $n=92$} & p value \\
\hline & $n$ & $\%$ & median & $n$ & $\%$ & median & $n$ & $\%$ & median & \\
\hline $0-10$ & 140 & 63.6 & 10.5 & 82 & 64.1 & 8.0 & 58 & 63.0 & 7.5 & $0.055 \times 2=5.821$ \\
\hline $11-16$ & 39 & 17.7 & & 23 & 18.0 & & 26 & 28.3 & & $0.595 Z=-0.532$ \\
\hline $17-20$ & 41 & 18.6 & & 23 & 18.0 & & 8 & 8.7 & & \\
\hline \multicolumn{11}{|c|}{ Disturbed sleep } \\
\hline \multirow[t]{2}{*}{ Score } & \multicolumn{3}{|c|}{ Total, n=220 } & \multicolumn{3}{|c|}{ Male, $n=128$} & \multicolumn{3}{|c|}{ Female, $n=92$} & $p$ value \\
\hline & $n$ & $\%$ & median & $n$ & $\%$ & median & $n$ & $\%$ & median & \\
\hline $0-10$ & 104 & 47.3 & 10.0 & 60 & 46.9 & 10.5 & 44 & 47.8 & 9.5 & $0.099 \times 2=4.619$ \\
\hline $11-16$ & 79 & 35.9 & & 41 & 32.0 & & 38 & 41.3 & & $0.672 Z=-0.423$ \\
\hline $17-20$ & 37 & 16.8 & & 27 & 21.1 & & 10 & 10.9 & & \\
\hline
\end{tabular}

$\%$ percentage; $x 2$ value of chi-square test; $Z$ value of Mann-Whitney $U$ test 


\section{Overall evaluation of the sleep scale by individual domains}

In the domain Nocturnal motor symptoms in the whole group, $140(63.6 \%)$ respondents reported score in the range from $0-10 ; 75(34.1 \%)$ respondents reported score from 11-16; 5 (2.3\%) respondents reported score 17 and more, with the median of score 9.0. In the domain of Nocturnal symptoms of Parkinson's disease in the range from 0-10 reported score $140(63.6 \%)$ respondents; in the medium range from 11-16 scored 39 (17.7\%) respondents; $41(18.6 \%)$ respondents reported score 17 and more. The median score reached value 10.5. In the Disturbed Sleep domain, median of score 10.0, $104(47.3 \%)$ respondents reported score in the range from $0-10 ; 79(35.9 \%)$ respondents reported score from 11-16; 37 (16.8\%) respondents scored 17 and more points (Figure 2).

\section{Overall evaluation of the sleep scale in individual domains and by sex}

Men and women achieved similar results in all domains. In the domain Nocturnal motor symptoms, men reported scores in the range of 010 in the number of $82(64.1 \%)$ and women in the number of $58(63.0 \%)$. In the range from 1116 points, $41(32.0 \%)$ men and $34(37.0 \%)$ women reported the given score. Scores higher than 17 points were reported by $5(3.9 \%)$ men and $0(0 \%)$ women. These differences in men and women proportions were not statistically significant $(\mathrm{p}=0.410)$ by chi-square test. The median score reached value 8.5 in men while 8.0 in women. This difference was not significant by Mann-Whitney U test with p value 0.819 .

In the domain Nocturnal symptoms of Parkinson's disease in the range from 0-10 was reported

Figure 3: Total sleep scale scores by stage of disease.

\begin{tabular}{|c|c|c|c|c|c|c|c|c|c|c|}
\hline \multicolumn{11}{|c|}{ Nocturnal motor symptoms } \\
\hline \multirow[t]{2}{*}{ Score } & \multicolumn{3}{|c|}{ Total, $\mathbf{n = 2 2 0}$} & \multicolumn{3}{|c|}{$\begin{array}{c}\text { Early stage } \\
\text { of the disease, } \\
n=123\end{array}$} & \multicolumn{3}{|c|}{$\begin{array}{c}\text { Advanced stage } \\
\text { of the disease, } \\
n=97\end{array}$} & \multirow[t]{2}{*}{$p$ value } \\
\hline & $\mathbf{n}$ & $\%$ & median & $\mathbf{n}$ & $\%$ & median & $\mathbf{n}$ & $\%$ & median & \\
\hline $0-10$ & 132 & 60.0 & 9 & 54 & 43.9 & 11 & 78 & 80.4 & 10 & $0.001 \times 2=34.969$ \\
\hline $11-16$ & 85 & 38.6 & & 69 & 56.1 & & 16 & 16.5 & & $0.709 \quad Z=0.025$ \\
\hline $17-20$ & 3 & 1.4 & & 0 & 0 & & 3 & 3.1 & & \\
\hline \multicolumn{11}{|c|}{ Nocturnal symptoms of Parkinson's disease } \\
\hline \multirow[t]{2}{*}{ Score } & \multicolumn{3}{|c|}{ Total, $n=220$} & \multicolumn{3}{|c|}{$\begin{array}{c}\text { Early stage } \\
\text { of the disease, } \\
n=123\end{array}$} & \multicolumn{3}{|c|}{$\begin{array}{c}\text { Advanced stage } \\
\text { of the disease, } \\
n=97\end{array}$} & \multirow[t]{2}{*}{$p$ value } \\
\hline & $\mathbf{n}$ & $\%$ & median & $n$ & $\%$ & median & $n$ & $\%$ & median & \\
\hline $0-10$ & 125 & 56.8 & 9.5 & 54 & 43.9 & 9.5 & 71 & 73.2 & 9 & $0.004 \times 2=20.167$ \\
\hline $11-16$ & 64 & 29.1 & & 44 & 35.8 & & 20 & 20.6 & & $0.980 \quad Z=-0.532$ \\
\hline $17-20$ & 31 & 14.1 & & 25 & 20.3 & & 6 & 6.2 & & \\
\hline \multicolumn{11}{|c|}{ Disturbed sleep } \\
\hline \multirow[t]{2}{*}{ Score } & \multicolumn{3}{|c|}{ Total, $\mathrm{n}=\mathbf{2 2 0}$} & \multicolumn{3}{|c|}{$\begin{array}{c}\text { Early stage } \\
\text { of the disease, } \\
n=123\end{array}$} & \multicolumn{3}{|c|}{$\begin{array}{c}\text { Advanced stage } \\
\text { of the disease, } \\
n=97\end{array}$} & \multirow[t]{2}{*}{$p$ value } \\
\hline & $\mathbf{n}$ & $\%$ & median & $n$ & $\%$ & median & $\mathrm{n}$ & $\%$ & median & \\
\hline $0-10$ & 102 & 46.4 & 9 & 52 & 42.3 & 8.5 & 50 & 51.5 & 8.0 & $0.026 \times 2=7.273$ \\
\hline $11-16$ & 78 & 35.5 & & 41 & 33.3 & & 37 & 38.1 & & $0.905 \quad Z=-0.119$ \\
\hline $17-20$ & 40 & 18.1 & & 30 & 24.4 & & 10 & 10.3 & & \\
\hline
\end{tabular}

$\%$ percentage; $x 2$ value of chi-square test; $Z$ value of Mann-Whitney $U$ test 
by $82(64.1 \%)$ men and $58(63 \%)$ women, in the range from $11-16$ by $23(18.0 \%)$ men and 26 (28.3\%) women. Scores above 17 points were reported by $23(18.0 \%)$ men and $8(8.7 \%)$ women. Differences in men and women proportions in this domain was not significant using chi-square test $(\mathrm{p}=0.055)$. Men felt higher impact of the disease (median 8.0) compared to women (7.5), with no statistical significance $(\mathrm{p}=0.595)$.

In the domain Disturbed sleep, we found score $0-10$ in men in the number of $60(46.9 \%)$ and in women in the number of $44(47.8 \%)$. Scores between 11 and 16 were reported by 41 (32.0\%) men and 38 (41.3\%) women. We found scores above 17 in $27(21.1 \%)$ men and 10 $(10.9 \%)$ women. Using chi-square test, we did not significant difference in followed proportion $(\mathrm{p}=0.099)$ (Figure 2).

\section{Overall evaluation of the sleep scale in the individual domains and by stage of the disease}

We performed the analysis for individual stages of Parkinson's disease - early and advanced stage. Median total score was 9.5 in the early stage patients and 9.0 at the advanced disease patients with no statistical significance $(\mathrm{p}=0.477)$.

In the domain Nocturnal motor symptoms, respondents reported scores in the early stage of the disease in the range from $0-10$ in the number of $54(43.9 \%)$ and in the advanced stage in the number of $78(80.4 \%)$ respondents. In the range of $11-16$ points, $69(56.1 \%)$ respondents in the early stage of the disease and $16(16.5 \%)$ respondents in the advanced stage of the disease reported the given score. Scores higher than 17 were reported by $3(3.1 \%)$ respondents in the advanced stage of the disease. We found by the chi-square test significant difference $(\mathrm{p}=0.001)$ in the domain by the stage of disease, with the majority of patients at advanced stage in level of score $0-10$ points. Median score reached value 11 at early stage of disease while 10.0 at advanced stage. This difference was not significant by Mann-Whitney U test with $\mathrm{p}$ value 0.709 .

In the domain Nocturnal symptoms of Parkinson's disease in the range of 0 - 10 reported score $54(43.9 \%)$ respondents in the early stage of the disease and $71(73.2 \%)$ in the advanced stage of the disease. In the range from $11-16,44(35.8 \%)$ respondents in the early stage of the disease and
$20(20.6 \%)$ respondents in the advanced stage of the disease reported the given score. Scores above 17 were reported by 25 (20.3\%) respondents in the early stage of the disease and 6 $(6.2 \%)$ respondents in the advanced stage of the disease. We found out by the chi-square test significant difference $(p=0.004)$ in the domain by the stage of disease, with the majority of patients at advanced stage in level of score $0-10$ points. Median score reached value 9.5 at early stage of disease while 9.0 at advanced stage. This difference was not significant by Mann-Whitney U test with $\mathrm{p}$ value 0.980 .

In the Disturbed Sleep domain, we recorded score from $0-10$ in $52(42.3 \%)$ respondents in the early stage of the disease and in $50(51.5 \%)$ respondents in the advanced stage of the disease. Scores in the range of 11-16 were reported by 41 $(33.3 \%)$ respondents in the early stage of the disease and $37(38.1 \%)$ respondents in the advanced stage of the disease. We recorded score above 17 in $30(24.4 \%)$ respondents in the early stage of the disease and in $10(10.3 \%)$ respondents in the advanced stage of the disease. We found by chisquare test significant difference $(p=0.026)$ in the domain by the stage of disease, with majority of patients at advanced stage in level of score 0-10 points. The median score reached value 8.5 at early stage of disease while 8.0 at advanced stage. This difference was not significant by Mann-Whitney U test with p value 0.905 (Figure 3).

\section{DISCUSSION}

Sleep disorders in patients with Parkinson's disease are very common but remain underestimated because they are not commonly assessed in clinical practice (Jongwanasiri et al. 2014). The disease is mainly associated with impairment of motor function. However, it is less known, but in some cases more significant, that the disease may manifest itself in a wider range of non-motor symptoms, with several adverse consequences.

Non-motor symptoms occur in approximately $88 \%$ of patients. Non-motor symptoms are usually present in the early stage of the disease. Some symptoms, such as sleep disorders, precede several motor symptoms of the disease (Bostantjopoulou et al. 2016). For answering our assumptions about sleep disorders in respondents with Parkinson's disease, we chose the Parkin- 
son's Disease Sleep Scale $2^{\text {nd }}$ Revised Version (PDSS2).According to expert sources, PDSS-2 is a reliable, valid, accurate and potentially therapeutic tool for measuring sleep disorders in given disease. Unlike the first version, PDSS-2 has been expanded to include a spectrum of nocturnal sleep disturbances (Trenkwalder et al., 2011).

Najafi et al. (2013) reported a total PDSS-2 score in the group of patients - 55, indicating severe sleep disorders, while the mean total score in the control group was 20 . This study evaluated 34 patients with Parkinson's disease and 34 healthy in the control group (Najaf et al. 2013). In our research, the highest total score was 47 . We did not find values higher than 50 in the whole study group. Menza et al. (2010) showed in his study that sleep problems were very common and affect approximately three quarters of patients. The most common disorder was difficulty falling asleep at night. It is the difficulty of sleeping at night that can really affect any aspect of sleep. Other common sleep disorders were sleep apnea, behavioral disorders in REM sleep and restless legs syndrome (Menza et al., 2010).Piao et al. (2017) in his study reported a research sample of 218 respondents, which is almost identical to our sample. In his study, he reported the incidence of restless legs syndrome in $40.37 \%$, while in our research, the incidence of restless legs syndrome occurred in almost $33 \%$ of respondents. Suzuki et al. (2012) in a study on sleep disorders in patients with the disease observed that the incidence of restless legs syndrome ranged from 0.98 to $16 \%$. He also compared his results with the author Piao.He concluded that the higher frequency of restless legs syndrome in the Piao study may be due to differences in patients' age and duration of disease (Suzuki et al. 2012). The prevalence of restless legs syndrome in Chinese patients with Parkinson's disease is approximately $8-35 \%$, which is also close to our research. These symptoms often begin or worsen during a rest or evening (Hogl \& Stefani, 2017).

Najafi et al. (2013) pointed to an association between sleep disorders and disease duration. We did not deal with duration of the disease in our research. We dealt with the stage of the disease, where we were interested in the difference between the stage of the disease and the achieved score in the sleep scale. Respondents in the early stage achieved approximately the same score as in the advanced stage. Junho et al. (2018) found in his study that excessive daytime sleeping affects $40 \%$ of patients in the study and is associated with older age, restless legs syndrome, depressive and anxiety symptoms, and poorer sleep quality.Thorough assessment and management of sleep problems in patients with Parkinson's disease may contribute to improving the quality of life.

Lynet et al. (2017) observed 225 respondents with Parkinson's disease. The average age of the respondents was 65.7 years and the average duration of the disease was 8.18 years. Among the respondents, $53.8 \%$ reported difficulty falling asleep, $23.6 \%$ had excessive daytime sleeping, and $71 \%$ of patients were taking sleeping pills. In our research, we had an average age of 76.8 years. The lowest age for both sexes (genders) in the research sample was 60 years. Lyn et al. (2017) report $53.8 \%$ of respondents with difficulty falling asleep. Difficulty falling asleep in our survey, $16.36 \%$ of respondents rated the frequency of difficulty falling asleep as very often, i.e. 6 to 7 days a week. $10.91 \%$ of respondents rated the frequency of difficulty often, i.e. 4 to 5 days a week. The highest percentage (43.64\%) of respondents rated the frequency occasionally - 1 day a week. Smith et al. (1997) report that sleep disorders were significantly higher in women than in men. Sleep disorders occurred in $25 \%$ of men and $41 \%$ of women. In our research, we assumed that there is a difference in the sleep scale score between men and women with Parkinson's disease. Although the research showed differences between the sexes, this difference was not statistically significant.

Norlinah et al. (2009) conducted a national survey of 220 respondents with Parkinson's disease. The number of respondents is identical to our research. Sleep disorders at night were reported by 215 respondents. The most common problems were: difficulty staying asleep; sleep without waking up; frequent need to urinate at night. Despite these difficulties, $2 / 3$ of respondents rated the quality of sleep as acceptable or good. The average length of sleep was 6.5 to 7 hours, but approximately $8 \%$ of respondents reported less than 5 hours of sleep per night. Hypnotic or sedative drugs were used by $29 \%$ of patients to help with sleep. Only half of the patients told their physician about nocturnal problems (Norli- 
nah et al. 2009). Problems of staying asleep without waking up and the frequent need to urinate at night is part of the domain of disturbed sleep in the PDSS-2 sleep scale. The overall score for disturbed sleep was 20 . A score of 10 was assessed by $47.3 \%$ of patients. In the range from 11 to 20 points, $52.7 \%$ of respondents scored, when we can already talk about more serious sleep disorders in the domain of disturbed sleep. The frequency of difficulties in staying asleep and sleep without waking up was assessed by $52.73 \%$ of patients more than 4 days a week. The frequency of needing to urinate at night was assessed by $60 \%$ of patients more than 4 days a week. In this case, we agree with the result of Norlinah et al. (2009), who rated the overall quality of sleep as acceptable or good. In our research, $47.3 \%$ of respondents report good sleep more than 4 days a week and $52.3 \%$ of patients less than 3 days a week.

The aim of the study by Porter et al. (2008) were to describe in detail the frequency and nature of sleep disorders in a population of 122 respondents diagnosed with Parkinson's disease. Of the total number of 122 respondents, 27 (22\%) had PDSS- 2 scores above 40 points, which they rated as significant sleep disorders, with sleep fragmentation and nocturia being the most commonly reported problems. In our research, we recorded a scale score ranging from 21 to 40 in $67(31 \%)$ respondents and we recorded the highest score up to 50 in $38(17 \%)$ respondents. We evaluate this result as severe sleep disorders. We did not find any score higher than 50 in the entire research set. Chung et al. (2013) report that up to $60-76 \%$ of respondents with Parkinson's disease have a sleep disorder called insomnia. Nocturnal hypokinesia, nocturnal and early morning dystonia, and impaired mobility are considered as common causes. In practice, attention is focused on the motor symptoms of the disease and are probably considered to be the primary causes of sleep disorders. The frequency of muscle cramps that woke respondents from sleep in our survey was not high. $80(36.36 \%)$ respondents never experienced muscle cramps at night and 68 (30.91\%) respondents occasionally. We can see similar results in the morning painful position of the hands or feet. In 72 (32.73\%) respondents this problem never occurred and in $76(34.55 \%)$ respondents it occurred occasionally.
Almost all the authors of the research studies agree that sleep disorders in patients with Parkinson's disease are very common and occur in relatively high percentages, which was confirmed in our research sample. Disturbed sleep needs to be addressed from several aspects. It is a problem that cannot be underestimated, because it negatively affects the course of the disease, mental state and cognitive functions, thereby affecting the quality of life.

In nursing practice, nurses assess the physical aspects of the disease, such as tremor, rigidity, and postural instability in patients with Parkinson's disease. Motor symptoms of the disease are traditionally considered to be the most important features of the disease and, of course, are given the most attention both in research and in clinical practice. Nevertheless, the disease affects patients' lives in a broader sense than just physical harm. Many of the non-motorized aspects of the disease, such as the sleep disorders we investigate, are very common and significantly affect the daily lives of these patients. Disturbed sleep affects the patient's self-sufficiency and cognitive functions, which in turn significantly affect the patient's mental state and can cause depression.

\section{CONCLUSION}

Sleep plays an important role in a person's good health and well-being throughout life. Sufficiency of quality sleep protects our mental and physical health, quality of life and safety. Persistent lack of sleep can increase the risk of some chronic health problems. Disturbed sleep is very common and affects quite a high percentage in patients with Parkinson's disease.It can manifest itself as sleep fragmentation, insomnia, excessive daytime sleepiness and other sleep disorders. The role of nursing is to be interested in the problems of sleep disturbance in patients; to discuss healthy and quality sleep; to offer information on appropriate behavior in the field of sleep hygiene with an emphasis placed on improving sleep satisfaction. All patients should be informed of good sleep hygiene and should try to maintain a regular sleep plan.A better assessment of these aspects of the disease could significantly reduce these problems, thereby improving patients' quality of life. Nurses are key to providing effective clinical management to patients with Parkinson's disease. Patients need basic nursing care because 
they face common problems such as sleep disturbance. Nurses are ideal for assessing personal problems and difficulties, for providing educational and emotional support.They can help neurologists in assessing the physical and mental condition of the patient. Disturbed sleep affects the quality of life not only for the patient but also for the family. Therefore, there is a need for patients, relatives, nurses and caregivers to gain a better knowledge and understanding of the disease and to mitigate the impact of the disease on the patient's daily life.An important step is the involvement of health care institutions providing care for patients with Parkinson's disease in research studies that address various issues, not just sleep disorders. The results of research can then be applied in practice, which in turn can reduce the prevalence of disturbed sleep in patients.

\section{LIMITS}

We see the limits of our research in a relatively not common diagnosis, which makes it impossible for a higher number of respondents, therefore the results cannot be generalized to the entire population of patients with Parkinson's disease.

\section{ETHICAL ASPECTS AND CONFLICT OF INTEREST}

Authors declare that the study has no conflict of interest and the ethical aspects of the research were respected.

\section{REFERENCES}

1. BARES M et al. (2015) Atypical Parkinson's syndromes. $1^{\text {st }}$ edition. Praha: Galen.

2. BARGIOTAS P, SCHUEPBACH MWM, BASSETTI C., (2016) Sleep-wake disturbances in the premotor and early stage of Parkinson's disease. Current opinion in neurology, 29.6: 763-772.

3. BARTOLOMEI L, PASTORE A, MELIGRANA L, SANSON E, BONETTO N, MINICUCI GM et al.(2018) Relevance of sleep quality on care giver burden in Parkinson's disease. NeurolSci, 1:835-9.

4. BENETIN J et al. (2014) How to live with Parkinson's disease. $2^{\text {nd }}$ edition. Bratislava: Lundbeck Slovakia Ltd.

5. BOSTANTJOPOULOU S et al. (2016) Selfreported autonomic symptoms in Parkinson's disease: propertie soft he SCOPA-AUT scale. Hippokratia, 20.2: 115.

6. DOKTOROVA G (2018) Sleep and rest. In:Selected topics from nursing issues. Trnava: Typi Universitatis Tyrnaviensis.

7. DUSEK P (2010) Parkinson's disease and sleep. In: Parkinson, Parkinsono magazine. n. 31, p. 2-5.

8. HAVRANKOVA P et al. (2016) Non-motor symptoms of Parkinson's disease. $1^{\text {st }}$ edition.Olomouc: Solen s.r.o.

9. HOGL B, STEFANI A, (2017) Restless legs syndrome and periodic leg movements in patients with movement disorders: Specific considerations. Movement Disorders, 32.5: 669681.

10. CHUNG S et al. (2013) Insomnia and sleepiness in Parkinson disease: associations with symptoms and comorbidities. Journal of Clinical Sleep Medicine, 9.11: 1131-1137.

11. JONGWANASIRI S et al. (2014) Evaluation of sleep disorders in Parkinson's disease: a comparison between physician diagnosis and self-administered questionnaires. J Med Assoc Thai, 97. Suppl. 3: S68-77.

12. JUNHO BT et al.(2018) Clinical predictors of excessive daytime sleepiness in patients with Parkinson's disease. Journal of Clinical Neurology, 14.4: 530-536.

13. KALIA LV, LANG AE, (2015) Parkinson's disease. Lancet. 386 (9996): 896-912.

14. LIN YY et al.(2017) Sleep disturbances in Taiwanese patients with Parkinson's disease. Brain and Behavior, 2017, 7.10: e00806.

15. MAASS A, REICHMANN H (2013) Sleep and non-motor symptoms in Parkinson's disease. Journal of Neural Transmission, 120.4: 565-569.

16. MENZA M et al.(2010) Sleep disturbances in Parkinson's disease. Movement Disorders, 25.S1: S117-S122.

17. NAJAFI MR et al.(2013) Quality of sleep in patients with Parkinson's disease. International journal of preventive medicine, 2013, 4. Suppl. 2: S229.

18. NORLINAH MI et al.(2009) Sleep disturbances in Malaysian patients with Parkinson's disease using polysomnography and PDSS. Parkinsonism \& related disorders, 15.9: 670-674.

19. PIAO YS et al.(2017) Restless legs syndrome 
in Parkinson disease: clinical characteristics, abnormal iron metabolism and altered neurotransmitters. Scientific reports, 7.1: 1.

20. PLHAKOVA A (2013) Sleep and dreaming: scientific findings and their psychotherapeutic use. $1^{\text {st }}$ edition. Praha: Portál.

21. PORTER B, MACFARLANE R, WALKER $\mathrm{R}$ (2008) The frequency and nature of sleep disorders in a community-based population of patients with Parkinson's disease. European Journal of Neurology, 15.1: 50-54.

22. SHIN JY, HENDRIX CC, (2012) Management of patients with Parkinson disease. The Nurse Practitioner, 38.10: 34-43.

23. SMITH MC., ELLGRING H., OERTEL WH., (1997) Sleep disturbances in Parkinson's disease patients and spouses. Journal of American Geriatrics Society, 45.2: 194-199.

24. SOBREIRA-NETO MA, PENA-PEREIRA MA, SOBREIRA EST, CHAGAS MHN, FERNANDES RMF, TUMAS V et al.(2017) High frequency of sleep disorders in Parkinson's disease and its relations hip with quality of life. EurNeurol; 1:330-7.

25. SPIRA A et al. (2012) Objectively measured sleep quality and nursing home placement in older women. Journal of American Geriatrics Society, 60.7: 1237-1243.

26. SUZUKI K et al.(2012) Nocturnal disturbances and restlessness in Parkinson's disease: using the Japanese version of the Parkinson's disease sleep scale-2. Journal of the neurological sciences, 318.1-2: 76-81.10.

27. SWICK TJ (2012) Parkinson's disease and sleep/wake disturbances. Parkinson's Dis; 2012:205471.

28. TRENKWALDER C et al. (2011) Parkinson's disease sleep scale - validation of the revised version PDSS-2. Movement Disorders, 26.4: 644-652. 